\title{
Cost Comparison Model: Blended eLearning versus traditional training of community health workers
}

\author{
Mysha Sissine ${ }^{1 *}$, Robert Segan ${ }^{1}$, Mathew Taylor ${ }^{2}$, Bobby Jefferson ${ }^{1}$, Alice Borrelli ${ }^{2}$, Mohandas \\ Koehler $^{2}$, Meena Chelvayohan ${ }^{1}$
}

1. Futures Group International, Washington DC

2. Intel Corporation, Washington DC

\begin{abstract}
Objectives: Another one million community healthcare workers are needed to address the growing global population and increasing demand of health care services. This paper describes a cost comparison between two training approaches to better understand costs implications of training community health workers (CHWs) in Sub-Saharan Africa.

Methods: Our team created a prospective model to forecast and compare the costs of two training methods as described in the Dalburge Report - (1) a traditional didactic training approach ("baseline") and (2) a blended eLearning training approach ("blended"). After running the model for training 100,000 CHWs, we compared the results and scaled up those results to one million CHWs.
\end{abstract}

Results: A substantial difference exists in total costs between the baseline and blended training programs. Results indicate that using a blended eLearning approach for training community health care workers could provide a total cost savings of $42 \%$. Scaling the model to one million CHWs, the blended eLearning training approach reduces total costs by $25 \%$.

Discussion: The blended eLearning savings are a result of decreased classroom time, thereby reducing the costs associated with travel, trainers and classroom costs; and using a tablet with WiFi plus a feature phone rather than a smartphone with data plan.

Conclusion: The results of this cost analysis indicate significant savings through using a blended eLearning approach in comparison to a traditional didactic method for $\mathrm{CHW}$ training by as much as $67 \%$. These results correspond to the Dalberg publication which indicates that using a blended eLearning approach is an opportunity for closing the gap in training community health care workers.

Keywords: Cost of mHealth, Technology Costs, Community Healthcare Worker Training, mHealth, SubSaharan Africa, Human Resources for Health, Blended eLearning

Correspondence: Email: msissine@futuresgroup.com*

DOI: 10.5210/ojphi.v6i3.5533

Copyright @2014 the author(s)

This is an Open Access article. Authors own copyright of their articles appearing in the Online Journal of Public Health Informatics. Readers may copy articles without permission of the copyright owner(s), as long as the author and OJPHI are acknowledged in the copy and the copy is used for educational, not-for-profit purposes. 


\section{Introduction}

Worldwide projections indicate that to meet the current global health care demand we need to train another 4.3 million health care workers - doctors, nurses, midwives and other health care professionals [1]. The health care worker shortage is disproportionately affecting Africa where $25 \%$ of the global burden of the disease resides with only $3 \%$ of the global health workforce to confront it $[1,2]$. The shortage for community health care workers (CHW) in sub-Saharan Africa alone is approximately one million [3]. CHWs provide vital life-saving services to communities that do not have regular access to health services. As a result, human resources for health is one of the most pressing global health challenges for the development community today [1]. Response from donors and government agencies has been to increase programs, advocacy, and funding for training of health professionals including CHWs. There is a demand for low-cost, effective training mechanisms to increase the number of CHWs and improve the efficiency of existing health care workers.

Concurrent with the growing need for health care workers there has been an increase in mobile technology, user uptake, and supporting infrastructure. In sub-Saharan Africa the annual growth rate for mobile technology is $19 \%$ where networks coverage and user subscriptions are increasing [4]. To benefit from the growing uptake and infrastructure in mobile technology, development agencies, National Ministries, private sector and NGOs are using mobile health (mHealth) tools for successful and cost effective support of health data collection, surveillance, counseling, decision support, and supply chain management [5]. The surge in mobile technology uptake and use offers many opportunities including improved training of community health workers.

In an effort to explore the benefits of integrating mHealth technologies to help train the CHWs needed in Sub-Sahara Africa, the Dalberg Global Development Advisors published Preparing the Next Generation of Community Health Workers: The Power of Technology for Training in May 2012 [4]. The paper commissioned by the iHeed Institute, Barr Foundation, mHealth Alliance, and MDG Alliance, gathered input from a wide assortment of notable NGOs (e.g. WorldVision, UNICEF, Save the Children, Partners in Health, AMREF, Jhpiego, IntraHealth), Technology Companies (Intel, HP, Vodafone, DiMagi, Grameen, Millennium Villages, BRAC), Academia (Johns Hopkins, Open University), the Ministries of Health for Nigeria and Kenya, and the World Health Organization [4].

The Dalberg Report specifically set out to determine if technology can be "harnessed in transformative ways to address critical gaps in community health worker training in sub-Saharan Africa". [4] The report explored the concept using a blended eLearning approach for training health care workers, which in addition to classroom time, includes learning from content on mobile applications. The blended eLearning approach mixes live training with multimedia applications as an effective pedagogical way to foster interaction, repetitive learning, supervision and monitoring. The current model for training health care workers is a didactic classroom setting for training alone [4].

When compared to the current CHW training model, the Dalberg Report showed that the blended eLearning strategy is a promising, innovative and efficient approach to training CHWs. In addition to reducing costs for training, the blended eLearning approach could improve standardization of training materials and increase retention to course materials because of on- 
demand access to revisit course materials. A blended eLearning approach also includes multimedia materials, visuals and audio important for individuals with different learning styles or to assist learning for students with limited literacy and education background. Further, one study [6] indicates that rich multimedia content contributes to faster and better training but it is only being used in about $10 \%$ of training environments. Ninety percent of $\mathrm{CHW}$ trainings are using paper based content like flipcharts, handouts and textbooks.

The Dahlberg report concluded that a blended approach to learning was a valuable tool for costeffective and sustainable training. Up to eighty percent of the training content could be standardized and shared with the blended approach, and digital content is easier to transfer and localize. This is particularly relevant for the developing community where a blended eLearning approach can be used to scale up much needed training initiatives to meet health care demands and fill the community health worker gap.

Budgets for development programs are limited and cost is a critical consideration for implementation and ongoing use of a capability solution. Sustainability is determined by availability of skills to manage and support a solution and by the flexibility of a solution to adapt to evolving requirements. Using the results of the Dahlberg Report, our team set out to explore the question:

What is the cost for a blended eLearning approach as suggested by the Dahlberg Report and how does this differ from traditional didactic training costs?

To address this question our team created a costing model to forecast and compare the costs of two training methods (1) traditional didactic training and (2) blended eLearning approach. We will also explore how well these solutions scale to large populations, while being flexible enough to support differing requirements.

\section{Literature Review}

In order to gather information to support the analysis and research, we began with a literature review on PubMed in April 2014. Selected publications focused on research regarding cost of blended eLearning for community health care workers. Keywords used in the search included: model, forecasting, costs, comparative cost, mHealth, training, health care worker(s), global health, developing countries, and eLearning, technology. Initial search results returned over 200 articles, however most were excluded because not all studies were conducted in a global setting and were therefore not relevant to a low-income setting. Themes that emerged from the literature search are: 1) a new focus and growing interest in using eHealth and mHealth to strengthen learning for medical professionals both in domestic and international setting [7-10]; 2) lack of formal outcome evaluations of these technologies in developing countries and conclusive evidence evaluating programs [6-9,11]; and 3) lack of evidence regarding the cost of these eHealth and CHW training programs $[9,12,13]$. 


\section{Methods}

\section{Costing Model}

Using the results of the Dahlberg Report, our team set out to explore the question: What is the cost for a blended eLearning approach as suggested by the Dahlberg Report and how does this differ from traditional didactic training costs? To address this question our team created a costing model to forecast and compare the costs of two training methods (1) traditional didactic training and (2) training with a blended eLearning approach.

The cost model created is a prospective model, based on expected future in-country costs. It is not a model of current existing training programs in-country, however the inputs used to populate the model are based on real cost data from the literature [12], cost data from Intel Corporation and expert opinion from technical staff working with Futures Group in Nigeria. The model was built in Microsoft Excel 2010. All costs are listed in US Dollars.

The team used input data gathered from Nigeria to investigate the cost for the training of community health workers. Nigeria was selected because of the population size, importance within the region, and because Futures Group has a local presence which allowed for better access to reliable cost data during our data collection period in February 2014.

Our costing model compares two scenarios. The first is the baseline training which includes the input costs required to conduct a traditional didactic community health care worker training (baseline training). The second scenario includes the input costs of a blended eLearning training consisting of a reduced in-class training component, supplemented with out of the classroom eLearning activities (blended eLearning training). In addition to comparing eLearning training costs, we include and compare costs for technology and connectivity to support the ongoing data collection needs of the CHW. After running the model for training 100,000 CHWs across five years in each scenario we compared the results.

\section{Model Inputs}

The inputs applied to the model came from the literature [4,12], local Futures Group technical staff and Intel Corporation. The baseline training consisted of in-classroom training for 12 weeks in year one $[4,12]$. The blended eLearning training consisted of reduced in-classroom training to 6 weeks combined with external eLearning on a mobile device with interactive multimedia such as video, audio and visuals [4]. Cost associated the facility, classroom supplies, instructor travel, instructor per diem, instructor lodging, $\mathrm{CHW}$ per diem incentive, and $\mathrm{CHW}$ salaries were based on by expert opinion by Futures Group technical team. We estimated CHW annual salaries to be $\$ 960$ per year.

Futures Group technical staff also provided local Nigeria cost data for smart phones (Table 1), voice/ data connectivity and solar charging packs (Table 2). Costs included in the model for Year 1 includes device, connectivity and solar charger costs for each CHW. Years 2-5 includes inflated voice and data connectivity costs. We found that the average smart phone cost in Nigeria is $\$ 150$ and the average data cost is $\$ 40$ per month. 
Table 1: Comparison of smartphone costs across providers in Nigeria

\begin{tabular}{|l|l|l|}
\hline Service Provider & Smartphone Model & Cost (USD) \\
\hline Airtel & Nokia Asha 303 & 127 \\
\hline Airtel & Nokia Lumia 510 & 174 \\
\hline Airtel & Samsung Galaxy Young & 125 \\
\hline MTN & Infinix Race & 126 \\
\hline Glo & Nokia Lumia 520 & 174 \\
\hline Glo & Blackberry 9320 & 177 \\
\hline
\end{tabular}

Table 2: Comparison of data costs across providers in Nigeria

\begin{tabular}{|l|l|l|}
\hline Service Provider & Data Allowance & Cost (USD) \\
\hline Airtel & 4GB & 25 \\
\hline MTN & 4GB & 49 \\
\hline Glo & 4GB & 37 \\
\hline
\end{tabular}

A variety of devices and data connectivity options were reviewed to determine the best balance of technology costs and functionality to meet the needs of CHWs. In addition to overall cost of the training programs, consideration was given to device, connectivity, device charging requirements and device functionality to meet the ongoing data collection needs of CHWs.

Finally, we considered the use of a combination of a feature phone and a tablet computer rather than a smart phone for the blended eLearning training and ongoing data collection needs of CHWs. Based on the opinion of in-country staff, our model included the assumption that CHW would already own a feature phone therefore feature phone costs were not calculated in the model. Intel Corporation provided cost data for tablet devices. Tablets would have occasional connectivity, which offers CHWs participating in the blended eLearning training the ability to download and upload training materials and content from a "hot spot" or Wi-Fi enabled area and store them for offline use.

Other inputs into the model included inflation rates and attrition rates. Inflation rates incorporated into the model are $10.5 \%$ based on average escalation in Nigeria from January 2011- March 2014 [14]. Attrition rates of 5\% were also included in the model and based on published literature [12].

\section{Model Assumptions}

It is important to note the following assumptions that were made in the construction of the model.

- There would be one classroom for every $50 \mathrm{CHWs}$

- There would be one instructor for every $50 \mathrm{CHWs}$

- All instructors would need to travel to the training location and would require a per diem rate

- Each CHW would receive a Per Diem incentive of $\$ 103$ per month during inclassroom training 
- Each CHW would own a feature phone, therefore cost for purchasing a feature phone were not included in the model

- Each CHW would participate in a 20 hour refresher course which would take place in a classroom setting

\section{Results}

Based on our model, a substantial difference exists in total costs between the baseline and blended eLearning training programs. Results indicate that using a blended eLearning approach for training community health care workers in Nigeria will provide cost savings of 19.6 Million USD or a reduction of costs by $42 \%$ in classroom costs alone.

\section{Baseline Training Classroom Costs}

Table 3 provides details on the cost for the baseline training or traditional didactic training approach which would requires 12 weeks ( 3 months) of in classroom training. Total classroom cost is $\$ 47,094,000$ across five years for training a total of $100,000 \mathrm{CHW}$. Note that units are 120,000 because of the $5 \%$ attrition rate that is applied to the model.

Table 3: Classroom Cost Results Baseline Training

\begin{tabular}{|l|l|l|l|l|l|}
\hline Item & Units & $\begin{array}{l}\text { Number } \\
\text { Units }\end{array}$ & $\begin{array}{l}\text { Unit Cost } \\
\text { (USD) }\end{array}$ & $\begin{array}{l}\text { Total Cost } \\
\text { (USD) }\end{array}$ \\
\hline Classroom Supplies & /CHW & 120,000 & 36 & $4,320,000$ \\
\hline $\begin{array}{l}\text { Classroom Facility } \\
\text { Costs }\end{array}$ & /Classroom & 2,400 & 900 & $2,160,000$ \\
\hline $\begin{array}{l}\text { CHW Per Diem } \\
\text { Incentive }\end{array}$ & /CHW & 120,000 & 309 & $37,080,000$ \\
\hline Lodging for Trainers & /Trainer & 2,400 & 950 & $2,280,000$ \\
\hline $\begin{array}{l}\text { Travel/Transportation } \\
\text { for Trainers }\end{array}$ & /Trainer & 2,400 & 285 & 684,000 \\
\hline $\begin{array}{l}\text { Annual Refresher } \\
\text { Course (Y2-Y5) }\end{array}$ & /Training & 380,000 & 1.5 & 570,000 \\
\hline Total Baseline Training Costs & & & $47,094,000$ \\
\hline
\end{tabular}

\section{Blended eLearning Training Classroom Costs}

Table 4 provides details on the blended eLearning training, which supplements classroom time with out of the classroom mobile training applications that are rich with multimedia content. The in-classroom work is reduced to 6 weeks ( 1.5 months). The total classroom cost for this program is $\$ 27,540,000$ across five years for training a total of $100,000 \mathrm{CHW}$. An attrition rate of $5 \%$ is included. 
Table 4: Classroom Cost Results Blended eLearning Training

\begin{tabular}{|l|l|l|l|l|}
\hline Item & Units & Units & Unit Cost (USD) & Total Cost (USD) \\
\hline Classroom Supplies & /CHW & 120,000 & 18 & $2,160,000$ \\
\hline $\begin{array}{l}\text { Classroom Facility } \\
\text { Costs }\end{array}$ & /Classroom & 2,400 & 450 & $1,080,000$ \\
\hline $\begin{array}{l}\text { CHW Per Diem } \\
\text { Incentive }\end{array}$ & /CHW & 120,000 & 185 & $22,248,000$ \\
\hline Lodging for Trainers & /Trainer & 2,400 & 475 & $1,140,000$ \\
\hline $\begin{array}{l}\text { Travel/Transportation } \\
\text { for Trainers }\end{array}$ & /Trainer & 2,400 & 143 & 342,000 \\
\hline $\begin{array}{l}\text { Annual Refresher } \\
\text { Course (Y2-Y5) }\end{array}$ & /Training & 380,000 & 1.50 & 570,000 \\
\hline Total Blended Training Costs & & $27,540,000$ \\
\hline
\end{tabular}

\section{Classroom Cost Comparison}

One cost driver in this model are the costs associated with in-classroom training. Comparing the two scenarios for training community health workers, the baseline training method is more costly than the blended eLearning approach. Switching over to a blended eLearning training program would reduce the costs for training $100,000 \mathrm{CHW}$ in Nigeria by $42 \%$. These cost savings are a result of decreased classroom time, thereby reducing the costs associated with travel, trainers and supplies.

\section{Device Cost Comparison}

A variety of devices and data connectivity options were reviewed to determine the best value and balance of technology costs and functionality to meet the needs of the programs.

Costs of device, connectivity, device charging requirements and device functionality were considered. Devices and connectivity mechanisms generally fell into one of two groups - (1) costs associated with using smart phones and (2) costs associated with using a combination of feature phone and tablet with WiFi. Table 5 provides a comparison of these two groups. With cost the only consideration, it is clear that selecting a tablet with WiFi and feature phone would be the least expensive option. By selecting to use either a tablet and feature phone in a mHealth intervention, the program would eliminate the need for a monthly data package associated with a smartphone therefore reducing technology costs. Recognition is made that cost savings is based on occasional free $\mathrm{Wi}-\mathrm{Fi}$ accessibility which may not be available in all locations.

Table 6 depicts the cost savings once the technology is applied at scale to 100,000 CHW across a five year training program. Costs included in the model for Year 1 include technology purchase, data/voice connectivity, and purchase of a solar charger. Years 2-5 includes inflated data/voice connectivity costs. 
Table 5: Technology Cost Comparison for the Training Programs

\begin{tabular}{|l|l|l|}
\hline Cost & Smartphone Costs (USD) & $\begin{array}{l}\text { Tablet \& Feature Phone Cost } \\
\text { (USD) }\end{array}$ \\
\hline Device & 150 & 160 \\
\hline Connectivity (Annual)* & 660 & 180 \\
\hline Data (Monthly) & 40 & 0 \\
\hline Voice (Monthly) & 15 & 15 \\
\hline Solar Charger & 40 & 40 \\
\hline $\begin{array}{l}\text { Total (Device, Connectivity, } \\
\text { Charger) }\end{array}$ & 850 & 380 \\
\hline
\end{tabular}

*Annual Connectivity is based on Data Monthly + Voice Monthly

The feature phone provides instant communications though SMS and voice without the additional costs associated with a monthly data plan as would be required by the Smartphone. In addition, the tablet offers additional functionalities not found in the Smartphone like access to a USB drive for medical devices, file sharing, an office suite, multimedia training, medical journals, decision making support, lab and pharmacy information, full electronic medical record system (EMR) among others. The limitation of the tablet is that the CHW would need to have regular access to WiFi for communication of training assessments, patient status and population health data. Refresher training can be accessed through flash drives and direct downloads.

Table 6: Technology and Connectivity Cost Comparison for Trainings for One Hundred Thousand CHWs

\begin{tabular}{|l|l|l|l|}
\hline Year & $\begin{array}{l}\text { Smartphone with Data } \\
\text { (in Millions USD) }\end{array}$ & $\begin{array}{l}\text { Tablet \& Feature } \\
\text { Phone with Voice and } \\
\text { Wi-Fi (in Millions } \\
\text { USD) }\end{array}$ & $\begin{array}{l}\text { Tablet \& Feature } \\
\text { Phone Net Savings (in } \\
\text { Millions USD) }\end{array}$ \\
\hline Year 1 & 38 & 47 \\
\hline Year 2-5 & 85 & 93 & 248 \\
\hline Total & 341 & 131 & 295 \\
\hline
\end{tabular}

\section{Training Costs for One Hundred Thousand CHW}

By running the model including the classroom training costs with the feature phone and tablet we see that, a savings of $67 \%$ ( $\$ 314.5$ Million) can be achieved in comparison to the baseline training program (Table 7).

Table 7: Training and Supplies Cost Comparison for One Hundred Thousand CHWs

\begin{tabular}{|l|l|l|l|}
\hline & $\begin{array}{l}\text { Baseline } \\
\text { (in Millions USD) }\end{array}$ & $\begin{array}{l}\text { Blended } \\
\text { (in Millions USD) }\end{array}$ & $\begin{array}{l}\text { Net Savings } \\
\text { (in Millions USD) }\end{array}$ \\
\hline Classroom Training & 47.1 & 27.5 & 19.6 \\
\hline Smartphone & 426.0 & 0.0 & 295.0 \\
\hline Feature Phone/Tablet & 0.0 & 131.0 & 314.5 \\
\hline Total Cost & 473.1 & 158.5 & \\
\hline
\end{tabular}




\section{Scaling up Training Costs to One Million Community Health Workers}

When our model is scaled up to training one million community health workers and includes additional costs associated with CHW salaries, management and overhead expenses, the blended eLearning training approach that uses Wi-Fi tablets is still cost saving by $25 \%$ or $\$ 3.62$ Billion USD (Table 8).

Table 8: Savings from a Blended eLearning Training program for One Million CHWs

\begin{tabular}{|l|l|l|l|}
\hline Input & $\begin{array}{l}\text { Baseline (in Billions } \\
\text { USD) }\end{array}$ & $\begin{array}{l}\text { Blended eLearning (in } \\
\text { Billions USD) }\end{array}$ & Savings (\%) \\
\hline Device & 4.27 & 1.32 & 69 \\
\hline Training & 0.47 & 0.28 & 42 \\
\hline Overhead & 1.89 & 1.72 & 25 \\
\hline Salaries & 5.92 & 5.92 & 0 \\
\hline Management & 1.97 & 1.97 & 0 \\
\hline Total & 14.53 & 10.91 & 25 \\
\hline
\end{tabular}

\section{Discussion}

For an eLearning solution to be sustainable and scalable it must be low cost and flexible. It must be able to function with minimal or occasional connectivity. It must also enable measurements of its effectiveness to facilitate evidence for program evaluation and to further inform best practices. The program must also meet the requirements of local supportability and have the ability to adapt general content into local languages. As recommended in the Dalberg Report, mHealth content developers and eLearning content should disaggregate content from underlying technologies to improve the spread of content easily. In addition, the global health community should support investments in platforms that facilitate sharing content [4].

Ideally a technology solution would provide both training and job capabilities. Examples of this are data collection and reporting, communications, medical diagnostics decision support, medical record keeping.

\section{Limitations}

There are many differences between low resources countries and regions where infrastructure, culture, costs, literacy, and security of health data can vary. Due to this variation, there are several limitations and the result of this study may not universally apply to other regions or programs.

- First, there are infrastructure differences between countries adding complexity to generalize mHealth and eLearning approaches. Some countries do not have broadband infrastructure or internet access necessary to support the blended eLearning approach. The Dalberg Report pointed out that only 9.6\% of Africans use the internet and $40 \%$ of the Sub-Saharan African population is still not covered by cellular networks [4].

- Costs inputs will also vary depending upon the setting. Cost data used in this analysis was from Nigeria and results will likely differ in a different setting. 
Because of this, the savings as reported in this analysis may vary when applied to another country.

- The assumption of occasional free WiFi connectivity may not be appropriate in all settings. While the blended eLearning approach does not assume constant or even regular access to $\mathrm{WiFi}$; even occasional access to $\mathrm{WiFi}$ may not be realistic in certain settings.

- Cultural differences should be considered. In some countries gender differences may play an important role in access to technology. In some regions women do not have access to mobile devices limiting the success of a blended eLearning approach to training female $\mathrm{CHW}$. Literacy levels may also vary from country to country and can challenge some aspects of an eLearning program. In addition, user experience level may make a blended eLearning approach less effective for training CHWs.

- Standardization of digital learning modules can reduce costs and provide a baseline for quality assurance. The need for efficient training to meet the goals of training one million CHW's will require a coordinated approach that reduces the need for duplicate content development.

\section{Conclusion}

The results of this cost analysis indicate significant savings through using a blended eLearning approach in comparison to a traditional didactic training for the additional one million health care workers needed in sub-Saharan Africa.

Results indicate that training cost can be reduced by $42 \%$ when compared to a baseline traditional didactic approach. The cost savings are due to reductions in in-class room training time, cost associated with instructor travel, and device selection. These results correspond to the Dalberg publication which indicates that using a blended eLearning approach is an opportunity for closing the gap in training community health care workers.

Further analysis indicates that additional cost savings can be met by using a tablet with Wi-Fi rather than a smartphone with a data plan. When the tablet and feature phone combination was used a savings of $67 \%$ was achieved compared to the baseline approach using a smartphone with monthly data plan.

Using Nigeria as an example, this paper reports on a cost comparison between the traditional didactic approach (baseline) and the blended eLearning approach. There are however several limitations that arise when pinpointing and assigning cost data and country context. These include differences between countries with infrastructure, culture, costs, and literacy. Therefore, there are many factors to consider when determining the best method for training a health care workforce in a low resource country.

In the right setting, the impact of a blended eLearning approach for community health care workers is substantial. In addition to the potential for cost savings, there is promise for greater impact and retention because eLearning trainings can be shared and reviewed on-demand as refresher material. Course work in an eLearning format can also increase flexibility with scheduling and coordination [9]. The blended eLearning approach also increases standardization Online Journal of Public Health Informatics * ISSN 1947-2579 * http://ojphi.org * 6(3):e196, 2014 
of training and translates best practices to wide audiences quickly. Finally, working with educational materials in an electronic format prepares the workforce to interact with technology providing training beyond just the course material and into the realm of preparing individuals to work with the ever-increasing usage of eHealth and mHealth applications.

\section{References}

1. Aluttis C, Bishaw T, Frank MW. 2014. The workforce for health in a globalized contextglobal shortages and international migration. Glob Health Action. 7, 23611. PubMed

2. World Health Organization. The world health report 2006. 2006:209. http://www.who.int/whr/2006/en/.

3. Singh P, Sachs JD. 2013. 1 million community health workers in sub-Saharan Africa by 2015. Lancet. 382(9889), 363-65. PubMed http://dx.doi.org/10.1016/S0140-6736(12)62002$\underline{9}$

4. Dalberg Global Development Advisors. Preparing the next generation of community health workers: The power of technology for training. 2012.

5. Mendoza G, Okoko L, Morgan G, Konopka S. May 2013. mHealth compendium, volume two. Arlington, VA: African strategies for health project, Management sciences for health. 2013;2: September 15, 2014.

6. Marinopoulos SS, Dorman T, Ratanawongsa N, et al. 2007. Effectiveness of continuing medical education. Evid Rep Technol Assess (Full Rep). (149), 1-69. PubMed

7. Källander K, Tibenderana JK, Akpogheneta OJ, et al. 2013. Mobile health (mHealth) approaches and lessons for increased performance and retention of community health workers in low- and middle-income countries: A review. J Med Internet Res. 15(1), e17. PubMed http://dx.doi.org/10.2196/jmir.2130

8. van Velthoven MH, Car J, Zhang Y, Marusic A. 2013. mHealth series: New ideas for mHealth data collection implementation in low- and middle-income countries. $J$ Glob Health. 3(2), 020101. PubMed http://dx.doi.org/10.7189/jogh.03.020101

9. Ruggeri K, Farrington C, Brayne C. 2013. A global model for effective use and evaluation of e-learning in health. Telemed $J$ E Health. 19(4), 312-21. PubMed http://dx.doi.org/10.1089/tmj.2012.0175

10. Barker K, Omoni G, Wakasiaka S, Watiti J, Mathai M, et al. 2013. 'Moving with the times' taking a global approach: A qualitative study of African student nurse views of e learning. Nurse Educ Today. 33(4), 407-12. PubMed http://dx.doi.org/10.1016/j.nedt.2013.01.001

11. Lemay NV, Sullivan T, Jumbe B, Perry CP. 2012. Reaching remote health workers in Malawi: Baseline assessment of a pilot mHealth intervention. J Health Commun. 17(Suppl 1), 105-17. PubMed http://dx.doi.org/10.1080/10810730.2011.649106

12. McCord GC, Liu A, Singh P. 2013. Deployment of community health workers across rural sub-Saharan Africa: Financial considerations and operational assumptions. Bull World Health Organ. 91(4), 244-53B. PubMed http://dx.doi.org/10.2471/BLT.12.109660 
13. Kaplan WA. 2006. Can the ubiquitous power of mobile phones be used to improve health outcomes in developing countries? Global Health. 2, 9. http://dx.doi.org/10.1186/1744-8603-2-9

14. Trading Economics. Nigeria inflation rate. http://www.tradingeconomics.com/nigeria/inflation-cpi. Accessed 09/15/2014, 2014. 